\title{
Watching a Heron Colony at Horseshoe Lake
}

by Larry A. Morgotch, Yorkton

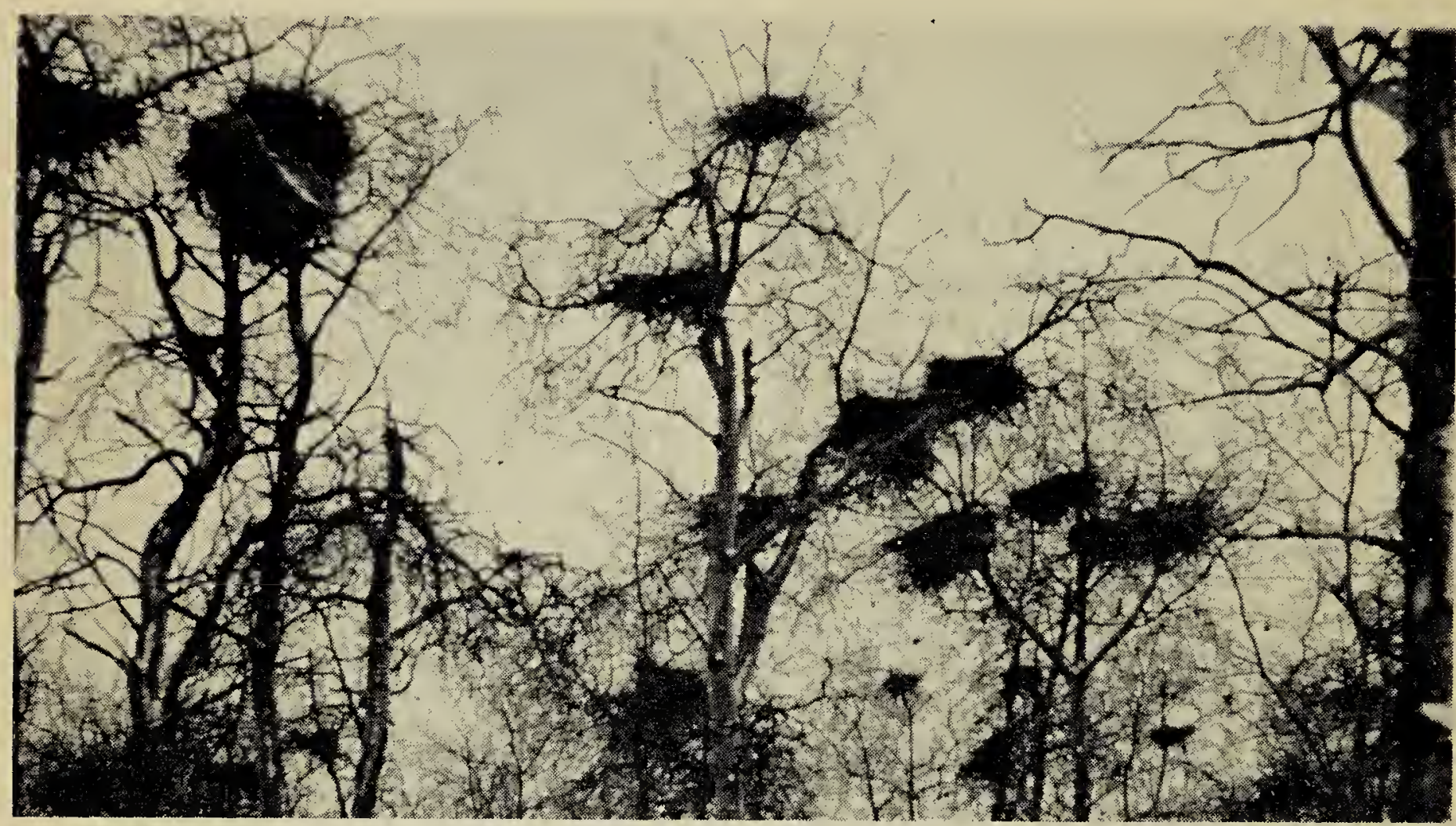

Fig. 1. The heronry at Horseshoe Lake.

This spring I spent many hours photographing a colony of Great Blue Herons at their nesting site on the south shcre of Horseshoe Lake. Horseshoe Lake is within the boundary of a game preserve approximately eighteen air miles northwest of Yorkton. Colonies of Great Blue

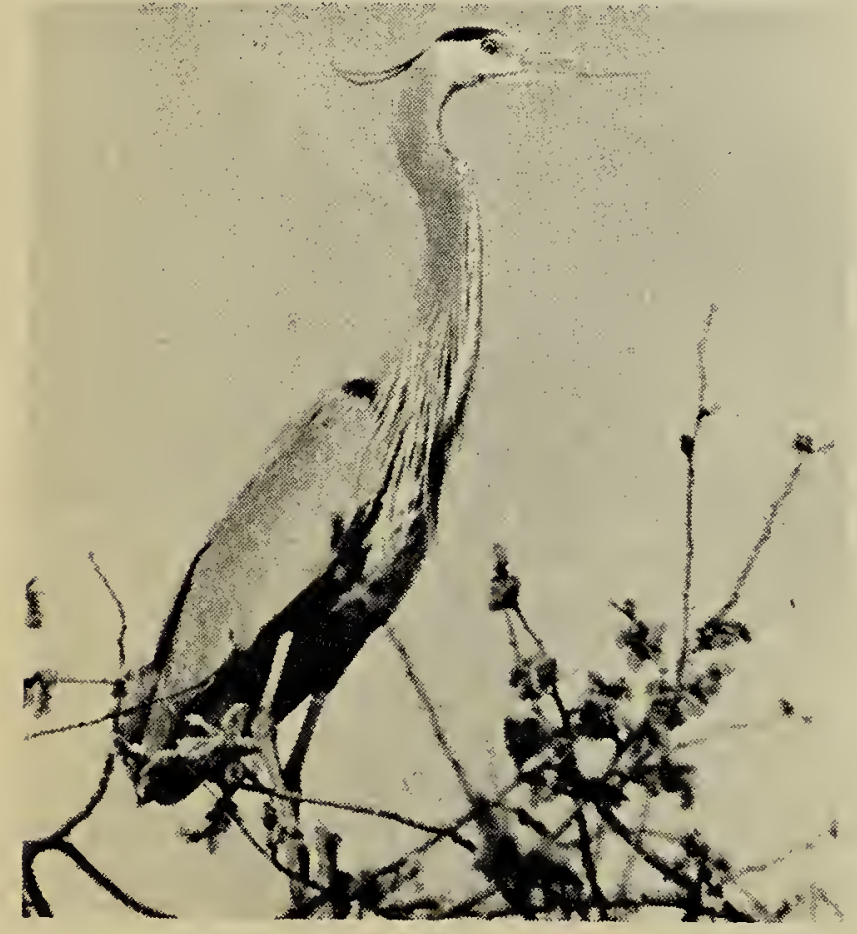

Fig. 2. Great Blue Horon at nest site, April 23, 1961.
Herons are not too common in the Yorkton area, although there are a number of good-sized heronries along the Qu'Appelle Valley.

About 30 herons gathered at Horseshoe Lake again this year to spend another summer repairing their nests, laying eggs and rearing their young. When I checked the lake on April 15, the herons had not yet arrived, but they were there by April 23 (Fig. 2), and the place seemed alive with them. On this day, while sitting behind a blind I had erected, I noticed a male heron standing quietly on a nest for perhaps a half hour. Then, as if at a signal, it began struggling to pull a length of dry stick from the very nest it was standing on. Finally, succeeding in freeing this stick, it just gave it a toss, caught it by the middle and hastily flew away with it. I was puzzled by its actions, as I do not think it uses a stick for mating purposes.

On May 13, when I was again able to return to the nesting site, I found three cogs in this nest. The herons appeared not to be as wary, and seemed more concerned then for the safety of their eggs. Returning June 9, I found the three eggs hatched and 
the fourth egg yet unhatched. On June 18 the fourth egg was missing; the three young, already increasing in size, were aware of my nearness, darting their beaks at me in defence (Fig. 3).

On July 2, only two of the three youngsters remained in the nest. I believe the missing young may have fallen out and been devoured by the badgers, as I noticed several of their burrows within the nesting area. The remaining two, when I appeared, would use their wings and beaks as well as their feet, in order to climb the branches away from me, occasionally darting their beaks at me. On this day, I found the dried up remains of a young heron which had fallen from another nest, suspended

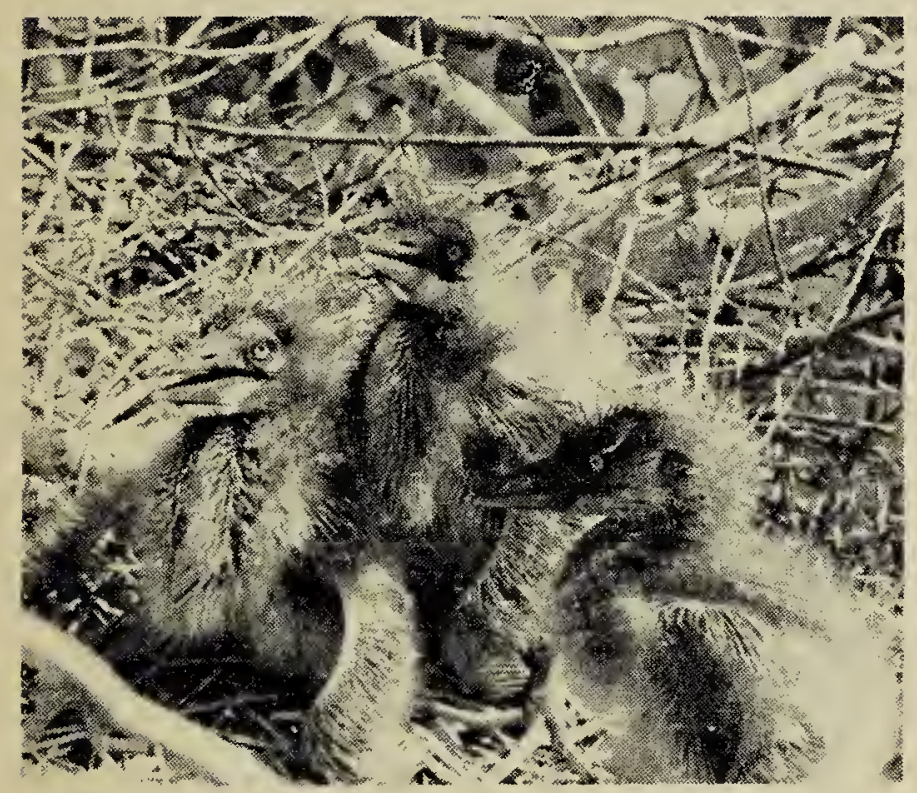

Fig. 3. Young herons nine-days old, June 18, 1961.

by its neck, its head caught between two sticks protruding from the edge of the nest.

On July 23, one of the two young was seen on the tree near the nest where it had remained (Fig. 4); the other was believed to be one of three young herons found in a clearing near the nesting site. On August 19, I found that all the young could fly. In the early part of the afternoon, not one heron could be spotted around the nest site, but an adult arrived at 6.30 p.m. With the setting sun they were coming in from several directions to ronst.

Some interesting facts about Great Blue Herons have come to my attention from my trips to photograph them. I have found that the adults seem less concerned for the safety of their young than for their eggs. It's

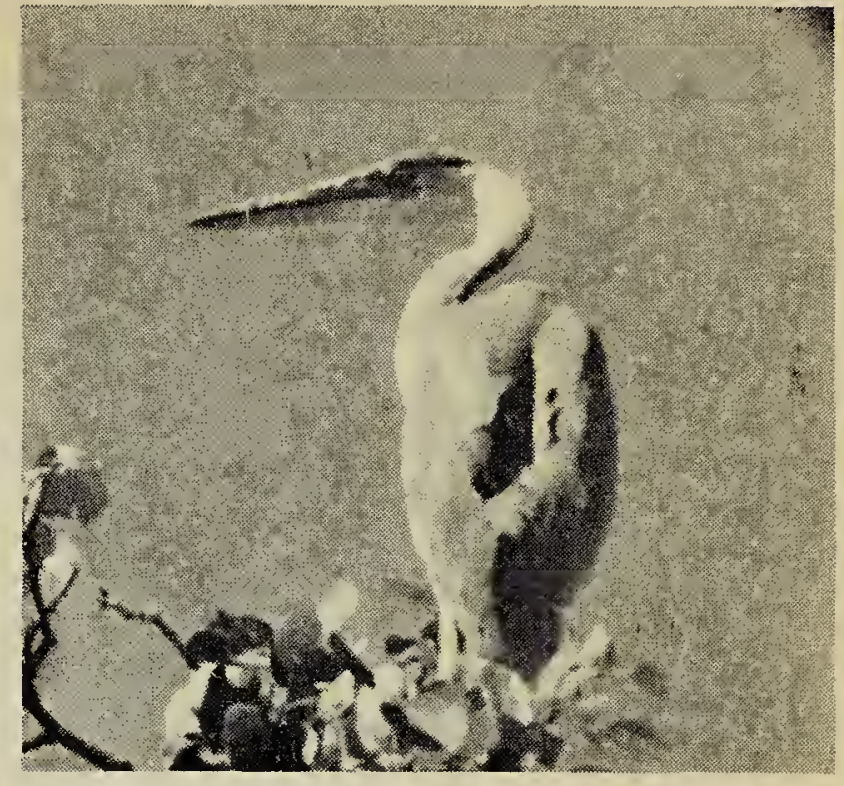

Fig. 4. Young heron perched near nest, July 23, 1961.

true many are miles away searching for food, but those within the nesting area would only croak, circle a couple of times, then leave, returning later after I had concealed myself. While I was climbing the trees to observe nests the adults made no attempt to attack or drive me away, as I had been told they would.

Several of these herons were spotted feeding on hay meadows overrun with grasshoppers. They mostly flew the three miles to Good Spirit Lake to feed there along the shore, but I have watched them hunting along the White Sand River, six miles away. I have also spotted three herons at Fulton Flats, nineteen air miles from their nesting site. This is, of course, no record for distance as herons travel long distances and spend most of the day searching for food.

\section{NEST RECORD CARDS}

Anyone who has not already sent in nest record cards kept for the 1961 season is urged to do so as soon as possible, so that this information may be summarized for a report in the Blue Jay. These cards are filed at the Museum where they may be used by people doing bird studies. Ouy contributors are to be congratulated for carrying on this worthwhile project.

Send cards to

Prairie Nests Records Scheme, c/o Saskatchewan Museum of Natural History, Regina. 